\title{
AN ECONOMETRIC FORECASTING MODEL FOR FOREIGN TRADE: EVIDENCE FROM TUNISIA
}

Terzi Chokri ${ }^{1 *}$, El Ammari Anis ${ }^{2}$,

*1 Faculty of Economic Sciences and Management of Sousse University of Sousse, Tunisia. E-mail: terisig5@yahoo.fr.

${ }^{2}$ Faculty of Economic Sciences and Management of Mahdia University of Monastir, Tunisia. E-mail: ammari_anis1@yahoo.fr

*Corresponding Author:

E-mail:terisig5@yahoo.fr (+21622658602)

\begin{abstract}
:
In this paper and without application because of the not availability of the data, the authors propose specific models in static and dynamic framework to analyze and forecast the evolution of the main components of the foreign trade of the Tunisian economy. For instance, they model and interpret the elasticities of imports and exports to changes in the prices and income. This approach thereby adds theoretical depth to a model that has a good forecasting performance. This paper is one among rare papers which focus on the modelling of the Tunisian foreign trade based on this approach.
\end{abstract}

Keywords: Foreign trade, forecasting, static frame, dynamic framework, elasticity.

JEL Classification: C10, C53, F10, F17. 


\section{INTRODUCTION}

Further to the more and deeper integration of the Tunisian economy in the global economy, the exchanges with foreign countries become more and more important, and our economy is more and more sensitive to the changes which intervene in the international environment. These transformations require a follow-up of the foreign trade of Tunisia in relationship with the world exchanges. In this respect, it is useful to call back (to remind) that the world trade evolved in a rhythm faster than that of the world production. Considering the liberalization perspectives and the globalization phenomenon, it is planned that this tendency continues with a stronger growth of the world exchanges with regard to the production's growth. The Tunisian exports have already known since 2010 the deep transfers. Raw materials, including hydrocarbons, represent no more than a low part. Manufactured goods establish nowadays the main part of our exports of goods with an equal part in approximately $80 \%$. The imports are also dominated by the manufactured goods which are in their majority, for the moment, complementary rather than competitors in the domestic production. However, the rival imports are more and more important especially with the program of tariff dismantling face to face of the European Union and the liberalization of the exchanges within the multilateral negotiation's framework.

For Tunisia, it is important to be an active partner in this expansion phenomenon of the world exchanges to maximize the liberalization earnings and minimize the transitional costs of adjustment. The opening involves expanding imports and thus challenges of competition more and more which the national production is confronted. This also involves the necessity of a strong growth of our exports which can result only from a better competitiveness of the Tunisian products. The increasing integration of the Tunisian economy in the global economy pulled deep transfers at the outer exchanges' level and the national production. While these transfers are beneficial in terms of efficiency and growth, especially in the way and the long term, they risk pulling costs. In this context, the follow-up of the foreign trade and its evolution with regard to (compared with) the national production turns out of a crucial importance.

A permanent follow-up of the evolution of the outer exchanges appears essential. The objective consists in informing the decision-makers of the performance of our foreign trade, at diverse levels of aggregation, in reference to the evolution of the world trade and the national production. This follow-up will be made on the basis of calculation of synthetic indicators allowing to meet the requirements at the same time of a liberalization and a globalization of the international trade and in concerns to support in any form whatsoever the national production against unfair practices of trade which risk to affect partially or totally the evolution of the productive system. The set of this information, synthesized and analyzed in time, offers to the decision-makers the possibility of taking the measures suited to strengthen the positive or promising trends or bring, where necessary, the necessary correctives in the presence of negative trends or in the presence of important imbalance of transition. Another essential point which will be the object of this paper is the forecast. The Tunisian foreign trade forecast is a complementary component in the follow-up especially when it is based on an econometric modelling allowing clearing up the decision-makers by means of the future projections essential for the implementation of the necessary strategies.

The rest of this paper is organized in the following way: the second section focuses on the theoretical review and empirical literature talking about the foreign trade forecast. The third section will present the econometric methodology adopted in both static and dynamic contexts. The conclusion will be the object of the fourth section.

\section{Literature review}

The foreign trade is also an important component of the final use approach to the GDP developments. The existence of trade deficits for a relatively long period of time might under some circumstances be a risk factor for the future growth prospects. On the other hand, the deficits might represent the process of capital accumulation and through the intensified investments increase the growth potential of the country. In all cases, developing an alternative instrument for short run export and import forecasting is justified by the need of providing better analysis and forming more accurate expectations about the economic development of the country (Grigor 2009).

The contemporary foreign trade theory encompasses a wide variety of research problems, analyzes the relations and causality between a number of economic processes and provides an ample field for empirical work. A large part of the traditional theory is focused on the causes of the foreign trade development and its consequences. The increasingly integrated world and the trend towards higher openness and interdependence between the countries led towards the incorporation of open economy features in almost all models for macroeconomic analysis and forecasting. In empirical work, however, there is always a trade-off between theoretical consistency and practical relevance.

Grossman and Helpman (1991) suppose that foreign trade factors and driving forces were expanded to include increasing returns to scale, monopolistic competition, preference for variety, market failures, while the predicted specialization is one of intra-industry trade. Gravity and endogenous growth models also contributed to the theoretical advances along with the theory of competitive advantage.

Among empirical foreign trade studies, Amano and Wirjanto (1994) modelled the Canadian foreign trade flows as a function of the agents' decisions in solving a dynamic optimization problem. The desired level of imports in their setup is a linear function of domestic demand and relative prices, and the solution of the problem leads to an Euler equation for imports. The coefficients of this equation are estimated in two steps, with co-integration techniques at the first and generalized method of moments (GMM) at the second. The estimated import elasticities with respect to domestic demand and relative prices are respectively 1.5 and -0.5 .

Senhadji and Montenegro (1999) analyzed the exports of 75 countries using the fully modified estimator of Phillips and Hansen (1990) in estimating the relations. The results about the export elasticity relative prices show an insignificant relation in the short run and a coefficient close to 1 in the long run. The export elasticities and the income of the trade partners are generally below 0.5 in the short run and around 1.5 in the long run. One of the conclusions of the study is that 
the export elasticities are lower in the industrial countries as compared to the developing countries. Mehta and Mathur (2003) reviewed the existing models for short run forecasting of Indian exports. The exports are generally modeled as a function of the demand of the trade partners of India and the development in relevant price indexes and exchange rates along with its autoregressive structure.

Bussiere, Fidrmuc and Schnatz (2005) analyze the trade integration of the Central and Eastern European (CEE) countries with the euro area using an augmented gravity model. In the panel data estimation, they find a significantly positive trade dependence on the economy size (GDP), neighbourhood, language similarity, trade union membership, price effect (captured by the real exchange rate dynamics), while the distance influences negatively the trade flows.

Keck, Raubold and Truppia (2010) have developed a time series model to forecast the growth in imports by major advanced economies in the current and following year. Both pure time series analysis and structural approaches that include additional predictors based on economic theory are used. Their results compare favourably to other trade forecasts, as measured by standard evaluation statistics, and can serve as a benchmark for more complex macroeconomic models. Chien, Ching and Gin (2008) suggested a modified regression model for forecasting the volumes of Taiwan's import containers. This article first identifies the contributions and shortcomings of previous empirical works. Then, a new modified regression model is proposed and built using data for the period 1989-2001. Finally, this paper compares the accuracy of the traditional regression model and this modified regression model for forecasting the volumes of Taiwan's import containers. The results show that this modified regression model proposed in this paper exhibits higher prediction accuracy.

Chon (2016) has proposed a new predictive system for international trade, based on an unobserved component model. He used the predictive system developed by Pástor and Stambaugh (2009), which is unlike other conventional predictive regression models. He derived an equivalent linear predictive regression from the predictive system, and explained why the proposed predictive system is able to achieve superior out-of-sample predictive power. When predictors are imperfect in an estimated equation, the equation fails to utilize all information from the predictors' past history, and unexplained variations are captured by residuals in the estimated equation. With the use of the predictive system, he can more effectively deal with the dynamics of imperfect predictors. For empirical illustration, results showed that, in the case of Korea's export and import growth rates, the predictive system has better out-of-sample predictive powers than the conventional regressions based on Root Mean Squares Error (RMSE). Results from an out-of-sample analysis show that, compared to the benchmark model, the predictive system improves forecast precision by $18.90 \%$ for the export growth rate, and by $7.95 \%$ for the import growth rate.

\section{Econometric methodology}

In order to check the robustness of the forecast, both static and dynamic modelling have been produced to help in term of providing constructive judgment about which forecast method is to be used for policy consideration.

\subsection{Static framework}

The object of this shutter is to propose an econometric model of the foreign trade which explains the equations evolution of export and import of the goods in volume on the basis of annual or quarterly series by using the developments of the non-stationary time series. The outcome of these models will consist in proposing to the decision-maker a model of forecast of the imports and the Tunisian exports according to the factors which determine them. We are interested here in the modelling of the foreign exchanges under the hypothesis that the exchanged goods are not perfectly substitutable in the domestic properties. The current situation, after the trade liberalization outside, allows to go to the direction which consists in taking place in a frame where the exchanged products establish no more substitutes perfected in the goods produced locally, in particular for 4 imports. Therefore, an assumption is avoided, the one according to which a given country is either importer, or an exporter of a given product.

The econometric analysis of the foreign exchanges of the goods and of their determiners presents a major interest especially when we wish to plan the sensibility in the time of the volume of imports and the exports in the various variations of income, prices of the domestic and foreign goods. Such estimations establish invaluable decision-making tools regarding projection of the volume of trade resulting from a change in the commercial policy or in that of the exchange rates.

Traditionally, a static formalization of the request of import or export results from a program of maximization of the consumers' utility under their constraint of income. The request of import can be formulated by means of a function of import which expresses the quantity of the imported

properties $(M)$ according to the nominal income $(Y)$, of the domestic price of the import $\left(P_{d}\right)$

expressed in local currency and of the price abroad $\left(P_{m}\right)$. The fundamental relation is expressed by the following function, written in real terms:

$$
M=f\left(\frac{Y}{P_{d}}, \frac{P_{m}}{P_{d}}\right)
$$


Under the hypothesis of absence of the consumers' monetary illusion and by supposing a log- linear relation, the equation of import demand expresses itself at the moment $t$ according to the following relation:

$$
\ln \left(M_{t}\right)=\beta_{0}+\beta_{1} \ln \left(\frac{Y_{t}}{P_{d_{t}}}\right)+\beta_{2} \ln \left(\frac{P_{m_{t}}}{P_{d_{t}}}\right)+\varepsilon_{t} \quad t=1, \cdots, T
$$

The use of a log-linear model presents the advantage to obtain estimated parameters which measure directly the elasticities of the import demand's with regard to the income $\left(\beta_{1}\right)$ and at the prices $\left(\beta_{2}\right)$. The report $P_{m} / P_{d}$ is a relative relationship of the prices which reflects the terms of the imported products competitiveness. During the estimations, the coefficient $\beta_{1}$ has to havea positive sign, whereas the coefficient $\beta_{2}$ has to be of negative sign. Indeed, the coefficient $\beta_{1}$ represents the elasticity income in the sense where the imports grow proportionally in the income variation. The coefficient $\beta_{2}$, of negative sign, expresses one elasticity price according to which the sensibility of the imports in the relative price's variation is of opposite sign.

The function of export is determined by the nominal world income $\left(Y^{W}\right)$, The domestic price of the export $\left(P_{x}\right)$ expressed in local currency and the price abroad $\left(P^{W}\right)$. The fundamental relation is expressed by the following function, written in real terms:

$$
X=g\left(\frac{Y^{W}}{P^{W}}, \frac{P_{x}}{P^{W}}\right)
$$

A log-linear relation, similar to that of the import request, expresses itself at the moment $t$ according to the following relation:

$$
\ln \left(X_{t}\right)=\beta_{0}+\beta_{1} \ln \left(\frac{Y_{t}^{W}}{P_{t}^{W}}\right)+\beta_{2} \ln \left(\frac{P_{x_{t}}}{P_{t}^{W}}\right)+\varepsilon_{t} \quad t=1, \cdots, T
$$

The estimated parameters measure directly the elasticities of the import demand with regard to the income $\left(\beta_{1}\right)$ and at the prices $\left(\beta_{2}\right)$. The report $P_{x} / P^{W}$ is a relative relationship of the prices which reflects the terms of the exported products competitiveness. During the estimations, the coefficient $\beta_{1}$ has to have a positive sign, whereas the coefficient $\beta_{2}$ has to be of negative sign. Indeed, the coefficient $\beta_{1}$ represents the elasticity income in the sense where the exports grow proportionally in the income variation. The coefficient $\beta_{2}$, of negative sign, express an elasticity price (prize) according to which the sensibility of the exports in the variation of relative price's variation is of opposite sign.

\subsection{Dynamic framework}

The import and export functions, described above, represent the long-run equilibrium relationships for import and export requests. As a consequence, the elasticities of the demand estimated establish long-term elasticities. Although the longrun effects of the determinants of import demand and export demand are useful for forecasting, long-run equilibrium adjustment times are of prime importance in terms of trade policy. Indeed, it is possible to envisage that for various reasons, the achievement of the situation equilibrium is not realized instantaneously.

As an example, the presence of adjustments costs to which the exporters are submitted in order to adapt to the demand, the incomplete nature of the information which they have on the market and the existence of diverse origin shocks are so many arguments which militate in favour of a dynamic modelling of the import's and export's demand of considered products so as to be able to appreciate the adjustment deadlines.

If the static framework of the exchanges can be appreciated from annual data, the dynamic modelling of the foreign exchanges favours the use of the quarterly data. In this context, a process of partial adjustment is adopted as method of introduction of a dynamic structure in the models of imports and export's demand. This approach allows introducing the delayed

endogenous variable $\left(M_{t-1}\right.$ and $\left.X_{t-1}\right)$ in the estimated equations.

For the import function, we suppose that the desired level of import demand $\left(M^{*}\right)$ is expressed as follows:

$$
\ln \left(M_{t}^{*}\right)=\alpha_{0}+\alpha_{1} \ln \left(\frac{Y_{t}}{P_{d_{t}}}\right)+\alpha_{2} \ln \left(\frac{P_{m_{t}}}{P_{d_{t}}}\right)+\varepsilon_{t} \quad t=1, \cdots, T
$$

Knowing that $\left(M^{*}\right)$ is observed, we suppose that the current level of import $(M)$ fits partially with its wished level. The relationship that links the import volume $(M)$ to its desired level $\left(M^{*}\right)$ is then written as follows:

$$
\ln \left(M_{t}\right)-\ln \left(M_{t-1}\right)=\lambda\left(\ln \left(M_{t}^{*}\right)-\ln \left(M_{t-1}\right)\right) \quad 0<\lambda<1
$$


By substituting the two previous relationships into each other, we obtain after rearranging the following dynamic import model:

$$
\ln \left(M_{t}\right)=\lambda \alpha_{0}+\lambda \alpha_{1} \ln \left(\frac{Y_{t}}{P_{d_{t}}}\right)+\lambda \alpha_{2} \ln \left(\frac{P_{m_{t}}}{P_{d_{t}}}\right)+(1-\lambda) \ln \left(M_{t-1}\right)+\varepsilon_{t} \quad t=2, \cdots, T
$$

According to the previous relation, the delay in the process of adjustment is measured by the parameter (1- $\lambda)$, while the $\underline{1-\lambda}$

average delay would be equal to $\bar{\lambda}$. Besides (In addition), the previous relationship states that any gap from the current volume of the imports at its wished level is partially corrected each period. In this respect, the knowledge of the speed of adjustment is essential for the implementation of the macroeconomic policy as well as for the calculation of the diverse (various) elasticities of the long-term demand.

The coefficients $\alpha_{1}$ and $\alpha_{2}$ indicate, respectively, the long-term elasticities of the demand compared with the income and to the price. Let us note that the coefficients $\lambda \alpha_{1}$ and $\lambda \alpha_{2}$ indicate the short-term elasticities of the demand with regard to the income and to the price.

By analogy to the import demand, it is possible to describe a dynamic relation for the export function using the partial adjustment procedure. The export relationship will be in the following form:

$$
\ln \left(X_{t}\right)=\lambda \alpha_{0}+\lambda \alpha_{1} \ln \left(\frac{Y_{t}^{W}}{P_{t}^{W}}\right)+\lambda \alpha_{2} \ln \left(\frac{P_{x_{t}}}{P_{t}^{W}}\right)+(1-\lambda) \ln \left(X_{t-1}\right)+\varepsilon_{t} \quad t=2, \cdots, T
$$

After carrying out the necessary tests of stationarity and co-integration (see annexe), the functions of import and export will be estimated by resorting to mechanisms with correction error (ECM). We retain following both specifications to be estimated by the MCO method:

$$
\begin{array}{r}
\Delta \ln \left(M_{t}\right)=\beta_{1} \Delta \ln \left(\frac{Y_{t}}{P_{d_{t}}}\right)+\beta_{2} \Delta \ln \left(\frac{P_{m_{t}}}{P_{d_{t}}}\right)+\beta_{3} \hat{\varepsilon}_{t-1}+\eta_{t} \quad t=2, \cdots, T \\
\Delta \ln \left(X_{t}\right)=\beta_{1} \Delta \ln \left(\frac{Y_{t}^{*}}{P_{t}^{W}}\right)+\beta_{2} \Delta \ln \left(\frac{P_{x_{t}}}{P_{t}^{W}}\right)+\beta_{3} \hat{\varepsilon}_{t-1}+\eta_{t} \quad t=2, \cdots, T
\end{array}
$$

In these two equations, indicates the residue estimated from the initial equations of the import's and export's models which establish a long-term estimation of the movements of import, respectively export.

This treatment suggests that, for each of the functions, the set of involved variables (their linear combination) should evolve along a trajectory of balance in the absence of important exogenous shocks. On the other hand, the real realization, estimated instantaneously, is generally situated below this long-term trajectory. At the econometric level, it is necessary to complete the relation by an immediate adjustment to get this gap between the long-term target and the effective realization. The residue estimated at the moment $(t-1)$ plays the role of this adjuster.

After this estimation phase, the results obtained and confirmed statistically, allow realizing forecasts to be made at near or far horizons of the evolution of the Tunisian imports and exports. On the basis of hypothetical values attributed to the variables of price and income, it is question of supplying the trend evolution of the imports and the exports at each future time.

\section{Conclusion}

In case of availability of necessary data, the proposed equations can beings used for the projection of the Tunisian foreign trade. These models offer a good theoretical wealth and produce forecasts of a quality at least so good, otherwise better, than that of the alternative models. The distinction between the static and dynamic frame based on the tests of stationarity and cointegration allowed to widen scopes of these models of forecast.

\section{Appendix}

One of the characteristics of the temporal serial macroeconomic data is their non-stationarity character (presence of persistent trend effect). In order to obtain coherent results, a preliminary statistical treatment turns out to be necessary. The appropriate methodology exists, and consists in testing the statistical nature of the used data, and in differentiating them, afterward, so much time until they answer the criterion of stationarity. In practice, the differentiation does not exceed the order 1 or 2 . After $d$ differentiations, the series, denoted $X_{t}$, will be said integrated by order

$$
d\left(X_{t} \rightarrow I(d)\right) \text {. }
$$

The statistical treatment of this stationarity property, operated on all the variables involved in the econometric models, can be done in a rough way through the Box and Pierce test (portemanteau test 1970). In a global procedure, with what this engender a lack of precision, this test makes it possible to have an idea on the existence of the phenomenon of stationarity or rather the persistence of a strong autocorrelation in the time of the series used. The principle of this treatment consists in establishing the functions of empirical auto correlations for any chronic $X_{t}, t=1, \ldots, T$. These are, in fact, the correlation coefficients in the order $k$, which are given by the following formula: 


$$
\hat{\rho}_{k}=\frac{\sum_{t=1}^{T-k}\left(X_{t}-\bar{X}\right)\left(X_{t+k}-\bar{X}\right)}{\sum_{t=1}^{T}\left(X_{t}-\bar{X}\right)^{2}} k=1, \cdots, K
$$

$k$ indicates the order of the delay, and $K$ the number of delays envisaged. Box and Pierce have built a statistics of test distributed according to the Chi-square law which we note $Q$ :

$$
Q=T \sum_{k=1}^{K} \hat{\rho}_{k}^{2} \rightarrow \chi_{(K)}^{2}
$$

A similar statistics, developed by Ljung and Box (1978), provides more accurate results in case the sample is small-sized (relatively short period). It is defined as follows:

$$
\mathrm{Q}^{*}=\mathrm{T}(\mathrm{T}+2) \sum_{\mathrm{k}=1}^{\mathrm{K}} \frac{\hat{\rho}_{\mathrm{k}}^{2}}{\mathrm{~T}-\mathrm{k}} \rightarrow \chi_{(\mathrm{K})}^{2}
$$

This formulation makes it possible to be placed oneself in two antagonistic situations of confirmation or not of stationarity for a given temporal series. This leads to testing the following hypothesis:

$$
\left\{\begin{array}{l}
\mathrm{H}_{0}: \rho_{1}=\cdots=\rho_{\mathrm{K}}=0 \\
\mathrm{H}_{1}: \exists \text { au moins } \rho_{\mathrm{k}} \neq 0
\end{array}\right.
$$

Under the null hypothesis $H_{0}$, the series is said to be stationary, thus generated by a process of white noise $\left(X_{t}=\mu+\varepsilon_{t}\right)$. Otherwise, the autocorrelation in the time will be confirmed, in which case it must be remedied in order to make the stationary series.

This approach, qualified of descriptive, must be refined by a more elaborate analysis in two directions. In a first stage, it is a question of specifying the order of integration of the series used -always at the univariate scale in order to make them stationary. This stage can be conducted through the Dickey and Fuller tests (1979).

The second stage consists in establishing a model compatible with the data used data by taking into account temporal univariées properties of the series. It is about tests of cointegration of Engle and Granger (1987) who allow testing the existence of a functional link between the considered variables.

We consider for any temporal series $X_{t}$, the general expression (unconstrained model):

$$
\Delta X_{t}=\alpha+\beta t+(\rho-1) X_{t-1}+\sum_{i=1}^{p} \theta_{i} \Delta X_{t-i}+\eta_{t}
$$

The Dickey and Fuller test (ADF augmented version) is based on the body of following hypotheses:

$$
\left\{\begin{array}{l}
H_{0}: \Delta X_{t}=\eta_{t} \quad / \quad \eta_{t} \rightarrow \operatorname{NID}\left(0, \sigma^{2}\right) \\
H_{1}: \Delta X_{t} \neq \eta_{t}
\end{array}\right.
$$

In practice, the procedure consists of estimating the unconstrained model above corresponding to the alternative hypothesis $H_{1}$ by the OLS method. Then, OLS estimation is carried out on the constrained model under the null hypothesis $H_{0}$. This last model is defined as follows:

$$
\Delta X_{t}=\alpha+\sum_{i=1}^{p} \theta_{i} \Delta X_{t-i}+\eta_{t}
$$

The statistic test is computed from the relative residual variabilities, respectively, of the constrained models $\left(S C R_{C}\right)$ and unconstrained $\left(S C R_{N C}\right)$. It is defined as follows:

$$
F=\frac{S C R_{C}-S C R_{N C}}{S C R_{N C}} \frac{T-k}{q}
$$

$T$ is the number of observations, $k$ the number of de parameters to be estimated in the unconstrained model, and $q$ is the number of restrictions to be tested. Besides, we notice that the statistic $F$ is not distributed according to the usual Fisher's z-distribution. Specific tables established by Dickey and Fuller using simulation allow to pull the adequate critical values and to compare them with the estimated values of $F$ from every sample of statistical data. 
In the same context and for the test of stationarity, besides ADF tests there are also the Phillips- Perron tests (PP 1988) and those of Kwiatkowski and al. (KPSS 1992).

The third stage is to consider co-integration tests as developed by Engle and Granger or by Johansen (1991). These tests are, however, theoretically limited because they adapt themselves only to series having the same order of integration, and more specifically integrated series of order 1 . The principle of the approach consists in testing whether a combination linear of several integrated variables of order 1 constitutes a stationary variable.

The relationship, once confirmed stationary, is called a cointegrating relationship. These conclusions prove the existence of a long-term equilibrium. This concept means, in the context of co-integration, that the observed relationship (cointegrating relationship) is maintained on average around a trajectory that is stable over time without deviations nor sensitive fluctuations. When a cointegrating relationship is confirmed by the test, the estimation of such a specification comes true by resorting to mechanisms with correction of error (is performed using error correction mechanisms) (ECM). They are partial adjustment mechanisms insofar which they ensure an adjustment of the gap that is created in the short term between the equilibrium trajectory (long-term) and the effective realization or estimated immediately. On the formal plan, the residue of the cointegrating relationship, capturing the short-term effect plays this role of adjuster by integrating it into the model as an explanatory variable.

\section{References}

[1].Amano, R.A and Wirjanto, T.S. (1994). The Dynamic Behaviour of Canadian Imports and the Linear-Quadratic Model: Evidence Based on the Euler Equation, Econometrics 9406002, EconWPA. Staff Working Papers 94-6, Bank of Canada.

[2].Box, G. E. P. and Pierce, D. A. (1970). Distribution of Residual Autocorrelations in Autoregressive-Integrated Moving Average Time Series Models. Journal of the American Statistical Association. 65: 1509-1526.

[3].Bussiere, M. Jarko, F. and Bernd, S. (2005). Trade Integration of Central and Eastern European Countries: Lessons from a Gravity Model. European Central Bank Working Paper, 545.

[4].Chien, C. C. Ching, W. C. and Gin, S. L. (2008). A modified regression model for forecasting the volumes of Taiwan's import containers. Mathematical and Computer Modelling, 47 (9- 10): 797-807.

[5].Chon, S. (2016). A Predictive System for International Trade Growth. KIEP Research Paper No. Working Papers-1603.

[6].Dickey, D. and Fuller, W. (1979). Distribution of the Estimators for Autoregressive Time Series with a Unit Root. Journal of the American Statistical Association, 74: 427-431.

[7].Engle, R. F and Granger, C. (1987). Co-integration and Error Correction: Representation, Estimation and Testing. Econometrica, 55: 251-276.

[8].Grigor, S. (2009). Econometric Forecasting of Bulgaria's Export and Import Flows. Bungarian National Bank, Discussion Papers, DP/77/2009.

[9].Grossman, G. M and Helpman, E. (1991). Innovation and Growth in the Global Economy. Cambridge: MIT Press.

[10]. Johansen, S. (1991). Estimation and Hypothesis Testing of Cointegration Vectors in Gaussian Vector Autoregressive Models. Econometrica. 59 (6): 1551-1580.

[11]. Keck, A. Raubold, A. and Truppia, A. (2010). Forecasting international trade: A time series approach. $O E C D$ Journal: Journal of Business Cycle Measurement and Analysis, OECD Publishing, Centre for International Research on Economic Tendency Surveys, 2009 (2): 157-176.

[12]. Kwiatkowski, D. Phillips, P. C. B. Schmidt, P. and Shin, Y. (1992). Testing the null hypothesis of stationarity against the alternative of a unit root. Journal of Econometrics. 54 (1-3): 159-178.

[13]. Ljung, G. M. and Box, G. E. P. (1978). On a Measure of a Lack of Fit in Time Series Models. Biometrika. 65 (2): 297-303.

[14]. Mehta, R. and Mathur, P. (2003). Short-term Forecasting of India's Export: Developing a Framework by Countries and Commodities. RIS-DP, 62.

[15]. Pástor, L. and Robert, F. S. (2009). Predictive Systems: Living with Imperfect predictors. The Journal of Finance, 64 (4): 1583-1628.

[16]. Peter, C. B. P. and Perron, P. (1988). Testing for a Unit Root in Time Series Regression. Biometrika, 75 (2): $335-$ 346

[17]. Phillips, P. C. B. and Hansen, B. E. (1990). Statistical Inference in Instrumental Variables Regression with I(1) Processes. The Review of Economic Studies. 57 (1): 99-125.

[18]. Senhadji, A. S. and Claudio E. M. (1999). Time Series Analysis of Export Demand Equations: A Cross-Country Analysis. IMF Staff Papers. 46 (3): 259-273. 